\title{
Structure determination techniques flex their muscles
}

\author{
Alexander J. Blake ${ }^{*[a]}$
}

Gas-phase electron diffraction (GED) has been around since $1928^{[1]}$, providing invaluable information about the structures of small molecules. Because the structural information is unaffected by interactions between neighbouring molecules, as seen to various degrees in the solid state, it can more readily be compared to the results of $a b$ initio theoretical calculations. As a result, GED provides reliable structures against which the results of theoretical calculations can be validated, while calculations can help to resolve structural features which are not well represented in the GED data ${ }^{[2]}$.

The GED technique (Figure 1) has undergone significant development since its inception, both experimentally and theoretically, with the result that it has delivered steadily more accurate and reliable structures. The technique is practiced by a small number of highly-experienced research groups, a reflection of both the challenges and limitations of the technique ${ }^{[3]}$. One of the major limitations is that GED data are effectively onedimensional, so that similar distances (bonded or non-bonded) overlap in the radial distribution function, such that the successful determination of more complex or difficult structures may depend on the availability of additional data from techniques such as $a b$ initio calculations, $X$-ray crystallography, liquid crystal NMR spectroscopy, or rotational spectroscopy ${ }^{[4]}$.
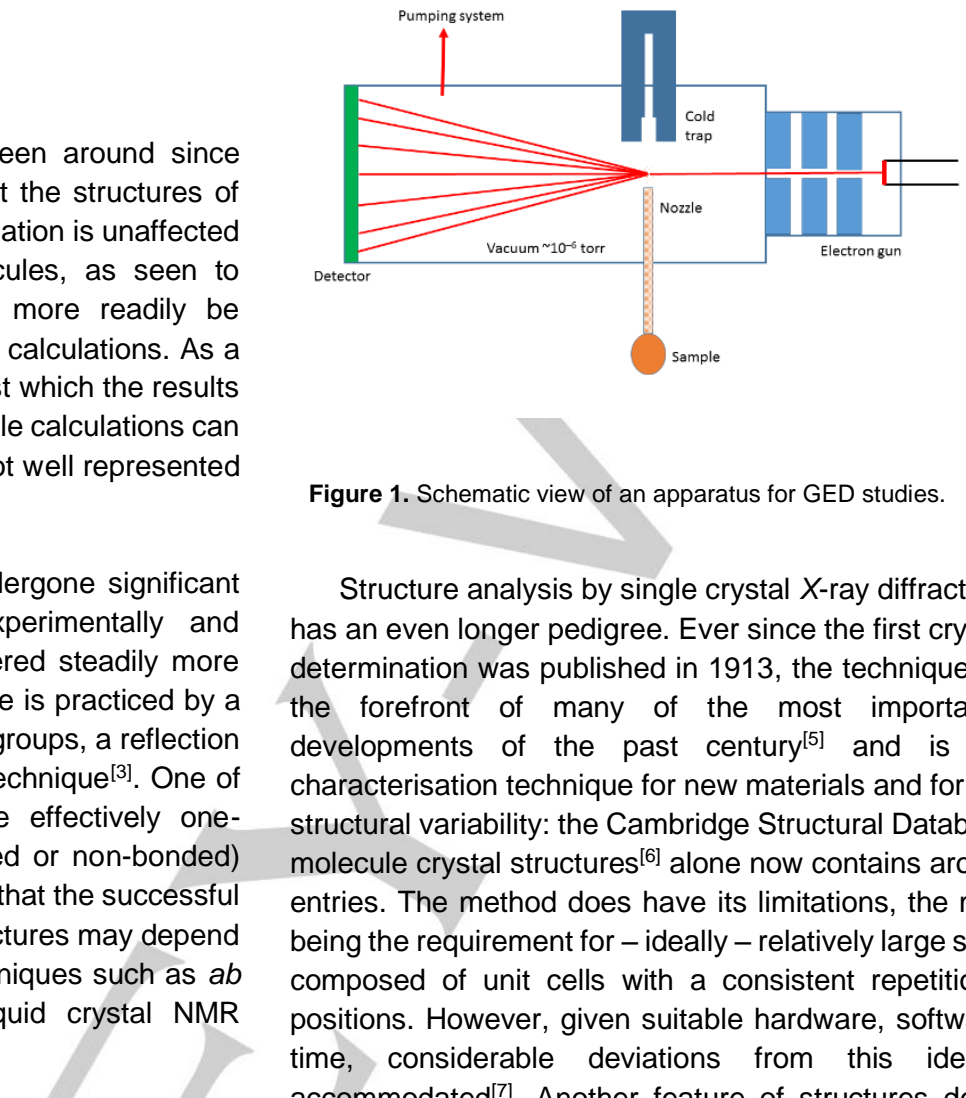

Figure 1. Schematic view of an apparatus for GED studies.

Structure analysis by single crystal $X$-ray diffraction (SCXRD) has an even longer pedigree. Ever since the first crystal structure determination was published in 1913, the technique has been at the forefront of many of the most important scientific developments of the past century ${ }^{[5]}$ and is a standard characterisation technique for new materials and for investigating structural variability: the Cambridge Structural Database of smallmolecule crystal structures ${ }^{[6]}$ alone now contains around 900,000 entries. The method does have its limitations, the most obvious being the requirement for - ideally - relatively large single crystals composed of unit cells with a consistent repetition of atomic positions. However, given suitable hardware, software, skill and time, considerable deviations from this ideal can be accommodated $^{[7]}$. Another feature of structures determined by SCXRD is that molecules are in close proximity to each other, the effects of which can range from insignificant to extreme. The field of crystal engineering ${ }^{[8]}$, which involves the design, construction and analysis of crystal structures of organic and metal-organic compounds, is based on the existence of significant intermolecular interactions in the solid state.

So, given the power and maturity of these techniques for structure determination, why is the successful determination of the structure of a simple molecule such as tetranitromethane (Figure 2a) in the gas-phase and the solid state such a big deal?

[a] Professor Dr Alexander J. Blake School of Chemistry

University of Nottingham

University Park

Nottingham NG7 2RD

UK

E-mail: a.j.blake@nottingham.ac.uk 
<smiles></smiles>

(a)<smiles></smiles>

(b)
Figure 2. (a) Conventional representation of tetranitromethane; (b) representation with arrows showing possible rotations about the $\mathrm{C}-\mathrm{N}$ bonds.

Part of the appeal of the Communication by Mitzel et al. ${ }^{[9]}$ lies in the resolution of many decades of uncertainty over the true structure of tetranitromethane. Allied to this are the shortcomings or apparently incompatible results of earlier studies, including those using GED ${ }^{[10 a, b]}$, infrared and Raman spectroscopies ${ }^{[10 c]}$ and SCXRD ${ }^{[10 d]}$. The article also stands out because of the impressive achievements of the authors in recognising the extremely high degree of flexibility in the tetranitromethane molecule and overcoming its consequences.

On their own, the static models normally employed in GED proved inadequate for such a flexible molecule, but the authors divined that the rotations about the $\mathrm{C}-\mathrm{N}$ bonds (Figure $2 \mathrm{~b}$ ) were both significant and highly correlated. Their innovative solution is a four-dimensional dynamic model involving variable values for the four $\mathrm{C}-\mathrm{N}$ torsions: their best fit was obtained using 82 pseudo-conformers to model the torsional molecular dynamics while refining the same parameters as for a static model. The techniques developed in order to determine the gas-phase structure of tetranitromethane are of great significance because of their general applicability to other flexible molecules, although the exact form of the modelling will depend on the particular molecule under study and the type of flexibility it displays.

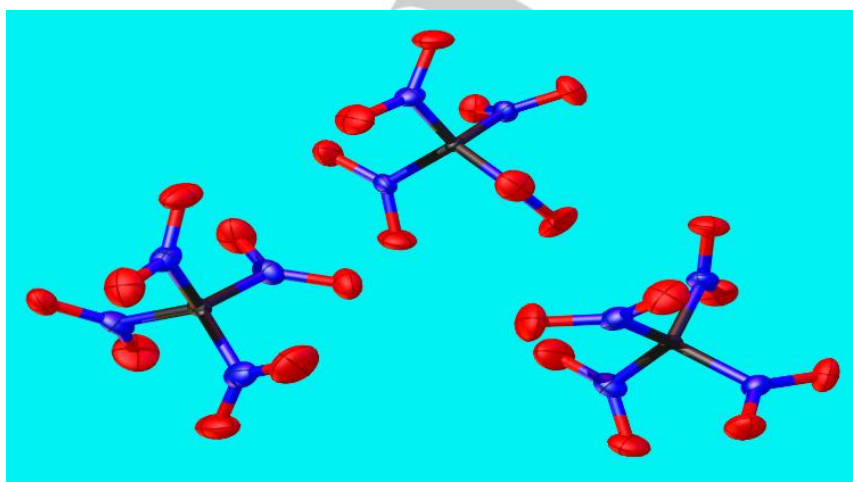

Figure 3. The three crystallographically-independent molecules in the low-temperature polymorph of tetranitromethane, as determined by SCXRD at $100 \mathrm{~K}$.

This same molecular flexibility was also on show in the structure determined at $200 \mathrm{~K}$ by SCXRD, where extensive disorder was detected in the higher temperature crystalline phase. The authors' refinement models involved differing degrees of disorder in both a higher-symmetry cubic space group and a lower-symmetry tetragonal one, but for none of these models were reliable molecular parameters obtained; the main conclusion was that the molecule was also highly flexible in the high temperature crystalline phase. However, recalling that vibrational spectroscopy ${ }^{[10 \mathrm{c}]}$ had previously suggested the presence of a phase transition at $174.4 \mathrm{~K}$, the authors cooled their crystal further and observed the transition at ca. $170 \mathrm{~K}$. Despite the presence of pseudo-merohedral twinning and three independent molecules in the asymmetric unit (Figure 3), they were able to obtain a reliable structure for the ordered lowtemperature phase in an orthorhombic space group at $100 \mathrm{~K}$. The variability of torsions about the $12 \mathrm{C}-\mathrm{N}$ bonds provides the final proof of the immense flexibility of the tetranitromethane molecule.

The authors have turned their "nightmare of flexibility" into a dream solution not only for tetranitromethane but potentially for other highly flexible molecules.

The author declares no competing interests.

\section{Acknowledgements}

The author thanks the University of Nottingham for support.

Keywords $\cdot$ molecular flexibility $\cdot$ dynamic model $\bullet$ phase transition $\cdot$ gas-phase electron diffraction $\bullet$ single crystal $X$-ray diffraction

[1] H. Mark and R. Wierl, Naturwissenschaften, 1928, 95, 778-786.

[2] See for example N. W. Mitzel, D. W. H. Rankin, Dalton Trans., 2003 3650-3662

[3] a) I. Hargittai, Structural Chemistry, 2005, 16, 1-3; b) S. Young, PhD Thesis, University of York, UK, 2015

[4] a) N. W. Mitzel, D. W. H. Rankin, Dalton Trans., 2003, 3650-3662; b) D. A. Wann, F. Blockhuys, C. van Alsenoy, H. E. Robertson, H.-J. Himmel, C. Y. Tang, A. R. Cowley, A. J. Downs, D. W. H. Rankin, Dalton Trans., 2007, 1687-1696; c) E. M. Brown, P. D. McCaffrey, D. A. Wann, D. W. H. Rankin, Phys. Chem. Chem. Phys., 2008, 10, 738-742; d) P. B. Liescheski, D.W. H. Rankin, J. Mol. Struct., 1989, 196, 1-19.

[5] See http://www.nature.com/milestones/milecrystal/index.html.

[6] C. R. Groom, I. J. Bruno, M. P. Lightfoot, S. C. Ward, Acta Crystallogr., Sect. B 2016, 72, 171-179. 
[7] W. Clegg, X-Ray Crystallography, Second Edition, Oxford University Press, 2015, Oxford.

[8] G. R. Desiraju, Crystal Engineering: The Design of Organic Solids, Elsevier, 1989, Amsterdam.

[9] Y. V. Vishnevskiy, D. Tikhonov, J. Schwabedissen, H.-G. Stammler, R. Moll, B. Krumm, T. M. Klapötke, N. W. Mitzel, Angew. Chem. 2017, volume, page range.

[10] a) A. J. Stosick, J. Am. Chem. Soc. 1939, 61, 1127-1130; b) N. I. Sadova, N. I. Popik, L. V. Vilkov, J. Mol. Struct. 1976, 31, 399-402; c) P. H. Lindenmeyer, P. M. Harris, J. Chem. Phys. 1953, 21, 408-414; d) T. Oda, T. lida, I. Nitta, J. Chem. Soc. Jpn. 1943, 64, 616-621. 
Entry for the Table of Contents (Please choose one layout)

Layout 1:

\section{HIGHLIGHT}

A historic challenge: Gas-phase electron diffraction and single crystal $X$-ray diffraction are both established techniques, but they were both pushed to their limits by the challenge posed by the highly flexible tetranitromethane molecule. New approaches had to be developed before the structure of the molecule could be elucidated.

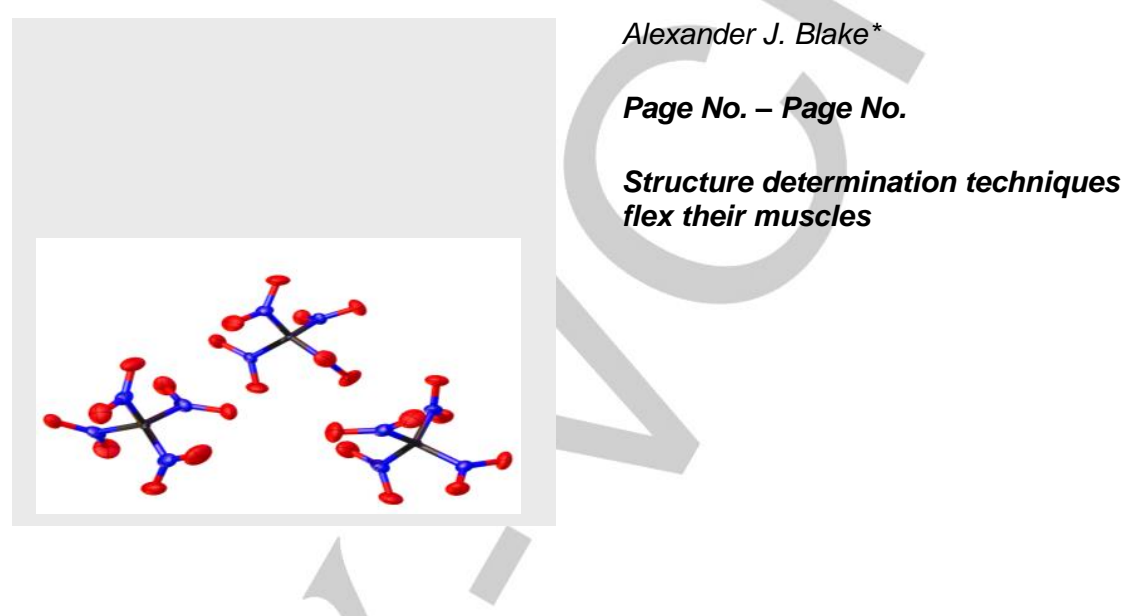

Layout 2:

\section{HIGHLIGHT}

((Insert TOC Graphic here))
Author(s), Corresponding Author(s)*

Page No. - Page No.

Title

Text for Table of Contents 